\title{
Feedback Management Software
}

\author{
Mohd Faizal Mohd Yunus ${ }^{1}$, Karkera Divesh Santosh ${ }^{2}$, Champaneri Mayank Naresh ${ }^{3}$, \\ Shaikh Khizra Usman Gani ${ }^{4}$ \\ ${ }^{1,2,3,4}$ Computer Engineering Department, Thakur Polytechnic, Mumbai, India
}

\begin{abstract}
Nowadays, educational Institutions are paying increasing attention to the views of Student's on the involvement in learning and teaching through reviews or feedbacks. Online Feedback System is a web application which provides base for the schools/colleges to conduct student's feedback online. The goal of the study was to develop an all in one feedback system serving both students and teachers. The system comprises of generation and analysis of teacher's feedback pages, summary, and a delivery of feedback. The system is developed for the all college students and staff members Also Students can give opinion about their faculty members. The purpose of this system is to collect information on learning experience as well as the about teacher's performance in the class. Student must login into the system, so as to give feedback. He has to login with his name and a password. He will give the feedback to the faculty member by subject wise. He has five options to choose from excellent, very good, good, satisfactory, poor. and student has to select one of the five options about faculty in his feedback form. Then after attempting every question has to submit his feedback with the system. This online feedback system is the perfect place to find feedback evaluated according to the requirements and it is the efficient one to get feedback analysis of students and staffs. In the proposed system, security is included, the result of which the feedback is only visible to authenticated users (Administrator or user with special privilege). Online feedback is an integral feature of evaluation of effective \& efficient learning \& teaching practices.
\end{abstract}

Keywords: feedback, management, system, project

\section{Introduction}

In today's world of online interaction, electronic education is becoming an important, of the academic domain. Faced with the strong growth of popularity of online courses, a need arises for a flexible, strengthened \& easily integrated online academic feedback delivery system. Teacher feedback system is a system which offers delivery of academic feedback online. This means that feedback is modified, helpful, also being accessible all the time, from anywhere in the world. Teacher feedback system is a web application which acts as a medium that teachers can use to deliver their feedback to students. This report consists an in-depth and detailed review of the development stages and processes, also justification for the need for such as system.

The 'Feedback management System' Approaches all about institutional and educational practices and processes that are taken into consideration, the student's concerns of the level of the knowledge they receive. This procedure explains that there is a good relationship between the students learning environment and teachers. In the existing system, students can give feedback about the lecturers manually on a paper where there are sets of well-defined questions. After giving feedback, papers are collected by the Staff and the overall marks for each subject and each lecturer is calculated. After that those all summary of grades is viewed by the head of the department which is given by the faculty. But by this process student can give feedback in online system which saves time and also once the feedback will be submitted it can't be changed.

We have developed faculty feedback system to provide feedback in an easy and consistent manner to the college HOD or principal. We call it faculty feedback system which delivers via student staff interface as online system which is acting as Service Provider. The primary focus of this project is to get familiar to VB.NET framework and C\# coding's. visual studio to provide a featured GUI which will be used by students. Many Web technologies are being applied in recent times with different purposes in Education particularly for which it is used in the proposed system for generating useful reports and the Semantic web tries to rebuild the present web concepts by adding a layer that will enable us in doing automatic processing of the web content, so that the data can be distributed and processed by both software as well as human-beings.

\section{Project Concept \& Product (Details of Product)}

Here in this web-app for issuing the feedback about thefaculty by students, this is named as Faculty feedback system. This system toprovide feedback in a easy and consistent manner to the college staffs and Head of the department. So we call it asFaculty Feedback System which delivers through the student staff interaction as web system is whichacting as a Service Provider by using this system we can make quick feedback about the facultyby students on time to HODs.

This project has four kinds of users Student, teachers, head of department and Admin. The student can givefeedback in online system provided by staff. Students and can give feedback about thelecturers.Lecturers can give feedback for peer faculty members and also self, Head of the department can give feedback for lecturers

These reports will be checked by the head of department He can view overall marks and grades obtained to the teacher and give this report to the principal and he can further give counseling tothe college staffs compared to the old or manual system, this online system is very easy to use and due to user-friendly interface it is easy to understand too. 


\section{International Journal of Science and Research (IJSR)}

ISSN (Online): 2319-7064

Index Copernicus Value (2015): 78.96 | Impact Factor (2015): 6.391

\section{Advantages}

The key features and advantages of online feedback system are listed below:

1)Cost-efficiency: using this system reduces the cost of paper and in person surveys which are conducted also the administration cost is reduced

2) Time saver: feedback softwaresaves a lot of time and effort.Through this system, you can quickly generate, collect and examine surveys. Performing all of these functions in one integrated web system saves you a extensive amount of time.

3) Convenience: It is very convenient for users to complete online surveys. Participants can fill out forms when they choose to and start and stop a survey at their ease.

4) Accessibility: Administering your surveys through an online system increases accessibility. Link of thesurvey can be sent via Gmail or any other social networking platform. Respondents then have a variety of ways to access the forms including mobile phones, laptops, tablets, computers, etc.

5)Reach \& Scalability: One of the greatest advantages of using online surveys is the reach and scalability. You can send surveys to thousands of people at the same time you take to send survey to single person. Also you can send surveys across the world and create forms in different languages.

6)Flexibility: Online surveys provide more flexibility in the design. in manual system participants can skip question but here this is not possible since every field is mandatory therefore the form will not get submitted till each and every questions are attempted

7)Anonymity: here admin also cannot view that which feedback was submitted by which student. with this feature student can give honest feedback without disclosing their identity

8)More Accurate: Since it is computer generated report the calculation error which generally comes in manual is reduced and hence providing you with more accurate reports

9)Results: As soon as student has completed the form, principal can view and analyze the reports. Through an online feedback management system, data / can be presented in formats like percentage, graphs, pie charts etc.

\section{Flow of the Software}

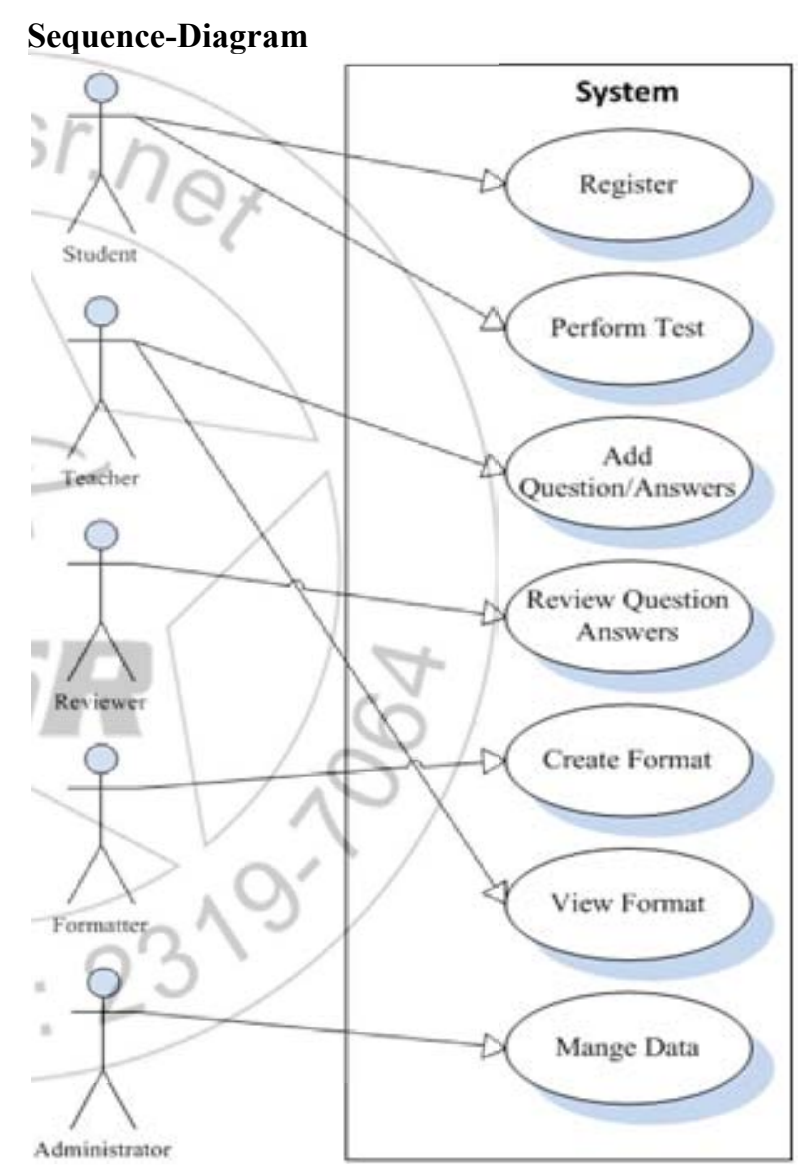

\section{User Profiles}

The following user types are expected for the feedback taking software:

\begin{tabular}{|l|l|}
\hline User & Brief Description of Use Actions \\
\hline Students & $\begin{array}{l}\text { Students can give feedback of teachers about their } \\
\text { teaching skills, body language, nature etc. }\end{array}$ \\
\hline Teachers & $\begin{array}{l}\text { Teachers can give feedback about student's } \\
\text { behaviour in class, communication with other } \\
\text { staffs etc. }\end{array}$ \\
\hline $\begin{array}{l}\text { Head of } \\
\text { department }\end{array}$ & $\begin{array}{l}\text { HODs can give feedback of teachers under his/her } \\
\text { dept. regarding punctualities, co-ordinations etc. }\end{array}$ \\
\hline Principal & $\begin{array}{l}\text { Principal can give feedback of HODs regarding } \\
\text { their leadership, task completion, troubleshooting } \\
\text { skills etc. }\end{array}$ \\
\hline
\end{tabular}




\section{Manufacturing Process \& Technology}

Basically, according to the plan discussed the first part is of the user interface. In this project since the calculation or the backend things are much complex and complicated we decide to make the actual look or the design of the product first after completion of that there will be only linking of the codesBehind the GUI

The technology used in here will be drag $n$ drop of components so once all the components are placed successfully it will be easier for just writing the functions of that key behind them and link all together. This was about the structure of the product i.e. backbone of our product coming towards the questions that will be asked in feedback those question will be type written in backend database may be in Ms-excel or SQL the access to these files will only be given to administration i.e. no other than administrator can change the set of question that will be asked in feedback write-up of questions will be done by administrator after the product has been developed

\section{Development Tools and Technologies}

\section{Front End}

1. VB.NET

Why vb?

- Object-Oriented Constructs

- Rapid Application Development (RAD) Support.

- Direct Access to the OS Platform

- Powerful Windows-based Applications

- Simplified Deployment

- Powerful, Flexible, Simplified Data Access

- Improved Coding

- COM Interoperability

- Drag and drop interface

\section{Back End}

1.SQL server

- Easy to use

- Reliable

- Integral

\section{Plant \& Machinery Required}

As this is a software product the one main thing required are high end computers

\section{Software and Hardware Requirement}

\begin{tabular}{|c|l|c|}
\hline Type & \multicolumn{1}{|c|}{ Software } & Hardware \\
\hline Computer & $\begin{array}{l}\text { 1. Windows 7 } \\
\text { 2. Visual studios 2008 } \\
\text { 3. SQL management studios }\end{array}$ & 1. RAM -512MB \\
\hline
\end{tabular}

\section{Location \& Infrastructure Required}

Can be installed in any computer lab in an institute where every pcs are connected via LAN

\section{Raw Materials, Consumables \&Utilities}

Raw materials used in this product are generally the code which are easier to get like open sources other than that the calculation, logical parts and GUI are done easily

\section{Applications}

This system can be used by Schools and Colleges to generate feedback

\section{Conclusion}

In today's world where education has become a basic necessity for every child/adult so to ensure that proper education Is being delivered or not their lefts only one way 'by taking feedback' so as to reduce the manpower the software is build which automatically takes the feedback turn by turn so as to not skip any of the member

The 'Feedback System' Approaches all about educational and institutional practices, the student's concerns about the knowledge they are being given. In the existing system student is provided with a paper in which there are set of questions with options where every option has some marks allotted the students are told to manually mark the options and from that further calculation is done and the papers are preserved. So as to reduce all this wastage of manpower, paper \& time this software is introduced in the existing system there are chances of editing the options after the feedback has been submitted by the higher authority for their greed purpose but in this software, once the student or peer faculty submits the feedback he himself or any other unauthorized person cannot edit that feedback again.

\section{References}

[1] en.wikipedia.org

[2] https://www.scribd.com/document/35586210/EpropertyProject-Report

[3] http://www.waikato.ac.nz/tdu/pdf/booklets/6_Assessmen tFeedback.pdf

[4] http://uir.unisa.ac.za/bitstream/handle/10500/4245/05Cha p\%204_Research\%20methodology\%20and\%20design.pd $\mathrm{f}$

[5] https://sg.finance.yahoo.com/news/5-ways-museumsusing-technology-175241413.html

[6] http://explorance.com/2013/07/10-key-advantages-ofusing-online-surveys-2/

[7] https://zapier.com/learn/forms-surveys/design-analyzesurvey/

[8] http://www.globalpartnership.org/education 